\title{
REDUÇÃO DA PESSOA A CONDIÇÃO ANÁLOGA À DE ESCRAVO NA SOCIEDADE CONTEMPORÂNEA: CAMINHOS PARA SUA ERRADICAÇÃO
}

\author{
Luciana Aboim Machado Gonçalves da Silva ${ }^{1}$ \\ Christiane Rabelo Britto ${ }^{2}$
}

\section{RESUMO}

O presente artigo visa demonstrar a existência de relações de trabalho, na sociedade hodierna, em condições análogas a de escravo, tendo em vista a busca exacerbada do lucro pelas empresas, inclusive para sobrevivência na sociedade globalizada de alta competitividade. Objetiva-se demonstrar que esse fenômeno causa grave desconsideração à dignidade da pessoa humana, necessitando do envolvimento de todos no combate deste problema, razão pela qual, essa temática não pode permanecer silenciada.

Palavras-chave: Direitos Humanos. Dignidade da Pessoa Humana. Trabalho Escravo Contemporâneo. Práticas Escravocratas Modernas. Erradicação do Trabalho Escravo.

\section{REDUCTION OF THE PERSON TO THE CONDITION ANALOGOUS TO THAT OF SLAVE IN CONTEMPORARY SOCIETY: WAYS FOR ITS ERADICATION}

\begin{abstract}
This article aims at demonstrating the existence of labor relations in today's society under conditions analogous to slavery, in view of the exacerbated pursuit of profit by companies, even for survival in a highly competitive globalized society. The objective is to demonstrate that this phenomenon causes serious disregard for the human person's dignity, causing the ineffectiveness of the fundamental human rights, so that, this theme can not remain silent.
\end{abstract}

Keywords: Human Rights. Human Dignity. Contemporary Slave Labor. Modern Slavorcratic Practices. Slave Labor's Eradication.

\section{INTRODUÇÃO}

\footnotetext{
1 Professora da Universidade Federal de Sergipe. Doutora em Direito do Trabalho pela Univesidade de São Paulo. Mestre em Direito do Trabalho, especialista em Direito do Trabalho e Processual Civil pela Pontifícia Universidade Católica. Pós-doutoranda em Direito pela Universidade Federal da Bahia e Università degli studi di Chieti. Vice-Presidente da "Asociación Iberoamericana de Derecho de Trabajo". Brasil; lucianaaboim@gmail.com

2 Mestranda em Direito da Universidade Federal de Sergipe - UFS. Pós-graduanda em Direito Constitucional pela Universidade Anhanguera - UNIDERP. Graduada em Direito pela Universidade Tiradentes- UNIT/SE. Integrante do Grupo de Pesquisa "Eficácia dos Direitos Humanos e Fundamentais: seus reflexos nas relações sociais", cadastrado pelo CNPQ. Brasil; christianebritto@yahoo.com.br
} 
O presente artigo refere-se à situação de trabalhadores em condições de labor que colidem com os princípios fundamentais da Lei Maior e, infelizmente, continuam sendo toleradas pelo nosso Estado Democrático de Direito, como é o caso da escravidão contemporânea vivenciada por milhares de brasileiros.

A exploração do homem como objeto existe desde os tempos mais remotos da humanidade. No Brasil, desde o seu descobrimento, essa exploração sempre teve como fundamento servir aos interesses daqueles que detêm o poder econômico, trazendo como consequência um sistema de desequilíbrio social.

As injustiças e desigualdades sociais, portanto, refletem-se na própria formação econômica do país, colocando o trabalhador em posição de maior submissão àqueles que detêm o poder econômico, resvalando em situações de labor em condições análogas à escravidão ainda nos tempos mais modernos.

A prática do trabalho em condições análogas a escravo é um dos assuntos em evidência na mídia e um dos graves problemas que o governo federal tem procurado solucionar através de políticas que visam a sua erradicação.

O foco dessa pesquisa é verificar os mecanismos que visam erradicar as situações de labor análogas ao escravo na sociedade atual, dentro do contexto socioeconômico na Ordem Jurídica vigente. Ademais, será demonstrado a importância da aplicação de uma Teoria da Justiça apta a fundamentar a efetivação do trabalho decente para a erradicação do trabalho escravo contemporâneo.

Para o desenvolvimento deste trabalho, fomentado pelas discussões oriundas do Grupo de Pesquisa "Eficácia dos Direitos Fundamentais: seus reflexos nas relações sociais" cadastrado no CNPQ, utilizando-se o método teórico-bibliográfico, através da análise de livros, artigos, revistas, entre outros, em meio impresso ou digital, a fim de que se possa demonstrar que o trabalho escravo é uma realidade na contemporaneidade, sendo imprescindível a discussão do tema, para que sejam traçados caminhos efetivos para o seu combate.

\section{A ESCRAVIDÃO CONTEMPORÂNEA NO CONTEXTO SOCIOECONÔMICO}


$\mathrm{Na}$ história da humanidade, não há como precisar um momento exato para o surgimento da escravidão. Como forma de trabalho humano, vê-se que a escravidão já significou um avanço, uma vez que, em tempos mais longínquos, o homem mais forte conquistava o território do mais fraco e se apoderava de seus bens. (TREVISAM, 2015, p. 48). O que se percebe, ao longo da evolução sociocultural, é que há variações no processo de escravidão relacionadas a fatores econômicos, políticos, sociais, culturais e religiosos.

O Brasil foi o último país a abolir a escravidão, o que ocorreu de forma gradativa devido a questões econômicas, época em que o país dispunha apenas da mãode-obra escrava para realizar a maioria das atividades laborativas, especialmente a agricultura. A Lei Áurea decretou o fim da escravidão em 13 de maio de 1888, entretanto o trabalho em condições análogas à de escravo persiste até a atualidade.

A escravidão moderna adquiriu nova roupagem ao não estar exclusivamente ligada à imagem de pessoas acorrentadas em senzalas, apresentando como traço identificador não apenas o cerceamento do direito de ir e vir, que passou a ser visto tanto na forma física como na psicológica, como também a jornada exaustiva e o trabalho degradante.

O governo federal reconheceu a existência do trabalho escravo contemporâneo em 2015, ano em que assumiu um compromisso perante a OIT no sentido de envidar esforços e medidas concretas para o combate e a erradicação do trabalho escravo, sendo considerado um dos primeiros países a reconhecer oficialmente esse fenômeno em seu território.

O marco emblemático para o reconhecimento de formas modernas de escravidão no Brasil ocorreu em 1995, com o caso de José Pereira, quando foi denunciado, junto à Corte Internacional, violações aos dispositivos legais da Declaração Americana sobre Direitos e Obrigações do Homem e da Convenção Americana sobre Direitos Humanos, ocorridas numa determinada fazenda, localizada no sul do Pará. O Brasil reconheceu a sua responsabilidade diante desse caso, comprometendo-se a assinar um Acordo de Solução Amistosa, o qual foi assinado no dia 18 de setembro de 2003. ${ }^{3}$ (OIT/ILO, 2010).

\footnotetext{
${ }^{3}$ Em setembro de 1989, José Pereira juntamente com seu colega de trabalho, apelidado de Paraná, tentaram fugir da fazenda de Espírito Santo, localizada na cidade Sapucaia, no sul do Pará/Brasil. Foram emboscados por trabalhadores portanto fuzil, responsáveis pela vigilância ostenciva, quando acertaram a
} 
Diante dessa situação, o Estado brasileiro tem empreendido esforços no sentido de cumprir o disposto no referido acordo. Entretanto, os agentes envolvidos na prevenção e no combate dessa prática vivenciam inúmeros problemas, sendo que um deles está ligado ao seu conceito legal, com a existência de uma infinidade de termos e entendimentos divergentes em relação aos mesmos para designar a ocorrência do trabalho forçado. Essa pluralidade de terminologias dificulta um consenso na significação do fenômeno e contribui para a realização de atuações diferentes entre os agentes envolvidos na erradicação do problema, fragilizando o valor destas ações.

A pesquisadora Shirley Silveira Andrade (2015, p. 207-209) desenvolveu uma pesquisa para chegar a uma conclusão sobre essas terminologias controversas. Para tanto, relacionou os diversos termos utilizados nos diplomas legais estrangeiros, tais como: escravidão na Convenção/1926 e no Tribunal Penal Internacional/2002; trabalho forçado ou obrigatório nas Convenções n ${ }^{\circ}$ 20/1926 e 105/1957 da OIT; escravidão e servidão na Declaração Universal dos Direitos Humanos/1948 e no Pacto Internacional dos Direitos Civis e Políticos/1966; escravidão, servidão, trabalho forçado ou obrigatório na Convenção Americana de Direitos Humanos (Pacto São José da Costa Rica)/1969. No Brasil, trabalho em condição análoga à de escravo no art. 149 do Código Penal e trabalho escravo no art. 243 da Constituição Federal.

$\mathrm{Na}$ conclusão da sua pesquisa, Andrade (2015) reconheceu a existência de políticas de combate em todas as esferas do Poder Público, porém a forma de compreensão dos fenômenos pelos diferentes poderes tem dificultado o combate. Informa que os auditores ficais procedem à autuação dos fazendeiros com a imposição de multas e obrigando-os ao pagamento das verbas indenizatórias, colhem as provas para a tipificação do delito e a devida responsabilização criminal, no entanto, a Justiça Federal não reconhece essa questão como crime.

Destaque-se que a diversidade de termos se refere à significação e entendimento do fenômeno no contexto das inúmeras sociedades existentes. Entretanto,

mão de José e ceifaram a vida de Paraná. Ato contínuo, José fingiu-se de morto e foi jogado com seu amigo na rodovia PA-150, a, aproximadamente, vinte quilômetros da cena do crime. José se dirigiu à fazenda mais próxima e pediu ajuda, sendo encaminhado para um hospital. Denunciou o ocorrido à Polícia Federal o vivenciado no momento da fuga, bem como as condições de trabalho estabelicidas na fazenda em que trabalhava. A Polícia fedderal efetuou o resgate dos 60 trabalhadores encontrados no local, sendo que os pistoleiros empreenderam fuga. A Comissão Pastoral da Terra, organização da Igreja Católica, responsável pela defesa dos direitos humanos e da reforma agrária; como, também, as organizaçoes não-governamentais Center for Justice and International Law (Centro pela Justiça e o direito Internacional) e Human Rights Watch encaminharam a denúncia para a Comissão Interamericana de Direitos Humanos (CIDH) da Organização dos Estados Americanos (OEA), em 22 de fevereiro de 1994. 
em que pese a existência de uma infinidade de termos, todos convergem para o fato de que essa prática aniquila a dignidade humana e transmuta a pessoa em objeto. ${ }^{4}$ Esse fato é reforçado com o posicionamento de Rina Gómes (2001), ao afirmar que:

Así la esclavitud no es una categoría fija para todo tiempo y lugar, assume formas y representaciones muy distintas de un lugar a otro, con una especificidad histórica, temporal y espacial, donde los individuos son trabajadores forzados en una sociedad concreta y traduce, o pone en evidencia, una forma de dominación, de control y uso de poder. La esclavitud es una forma de explotacíon que la distingue de otras formas por la dualidad de los sujetos sociales: son personas y son mercancias, y como personas son propriedad. (GÓMEZ, 2001, p.33).

Nesse contexto, é importante trazer a baila o posicionamento de Vanesa Rodríguez (2013):

Resulta necesario recordar que es el status o condición de una persona sobre la cual se ejerce todo o alguno de los poderes associados al derecho de propriedade; y la servidumbre es la sujecíon de una persona bajo la autoridad de otra con subordinación a la voluntad y los designios de otra sin que tenga opción a decidir, protestar o discrepar, con la total perdida de la libertad y con la consecuente despersonalización y captación de voluntad. (RODRÍGUEZ, 2013, p. 82).

Outro fato que contribui para o a tratativa divergente desse fenômeno pelos agentes envolvido na prevenção e repressão dessa realidade é o desconhecimento referente à diferenciação entre a escravidão ocorrida no período colonial e a escravidão contemporânea. Nesse sentido, a Organização Internacional do Trabalho (OIT), através do International Labour Office (ILO), no Brasil, aduz que as formas anteriores de escravidão eram legais, perenes, além de passar de uma geração para outra. Por sua vez, na escravidão moderna as vítimas são tratadas como mercadorias, há um poder de mando exercido sobre a pessoa temporariamente, sendo que a grande maioria dessas vítimas são migrantes de estados distantes do seu local de "exploração". Como forma de evidenciar essa diferenciação utiliza-se as expressões "trabalho escravo contemporâneo", "trabalho escravo por dívida", entre outros, para se referir a nova modalidade de escravidão. Na seara jurídica, emprega-se o termo "análoga" para se referir à escravidão contemporânea. (OIT/ILO, 2010, p. 40-41).

O esclarecimento dessa diferença é muito importante, posto que a imagem de escravos negros que habitavam as senzalas não retrata a figura do escravo na atualidade, muito embora sejam submetidos a maus-tratos herdados da escravidão colonial. Frise-se

\footnotetext{
${ }^{4}$ Para fins de terminologia adotada por esta pesquisa, utilizar-se-á os termos escravidão contemporânea, escravidão moderna e redução da pessoa a condição análoga à de escravo como sinônimos, a corresponder tanto o cerceamento da liberdade como à afronta a dignidade humana.
} 
que esse estereótipo do escravo na época colonial interfere no enfrentamento do problema, isto porque os agentes responsáveis pelo combate dessa prática muitas vezes descartam a configuração de trabalho escravo ao se depararem com realidades que não correspondem dos escravos de outrora, o que corrobora com a impunidade deste delito hodiernamente. Ademais, é justamente a impunidade do delito e o desconhecimento das legislações e dos direitos trabalhistas que favorece a perpetuação da escravidão contemporânea. (OIT/ILO, 2010, p. 41-42).

Pertinente às legislações em âmbito interacional, tem-se a Declaração Universal de Direitos Humanos (DUDH) que estampa a proibição do trabalho escravo nos $\operatorname{artigos} 4^{\circ}$ e $5^{\circ}$, no sentido de ser inadmissível a escravidão, a servidão, como também o tráfico de escravos. Resta, também, proibida a tortura e o tratamento cruel, desumano e degradante.

As Convenções no 29/1930 e 105/1957 da Organização Internacional do Trabalho (OIT). A primeira, denominada Convenção sobre Trabalho Forçado, trata da erradicação do trabalho forçado ou obrigatório e a de número 105, intitulada Convenção sobre a Abolição do Trabalho Forçado, coíbe o trabalho forçado ou obrigatório como forma de coerção ou de educação política; como forma de disciplina no trabalho; como castigo devido à participação em greve, como discriminação. Ambas as Convenções foram ratificadas pelo Brasil.

Desta forma, resta evidente que a comunidade internacional ecoa no sentido de reconhecer a proibição de atividades que reduzam as pessoas à condição análoga à de escravo. O trabalho escravo contemporâneo é tratado como uma afronta aos direitos humanos, uma vez que tolhe a liberdade do ser humano, aniquila a sua honra, promove a sua exploração e muitas vezes leva essas pessoas à morte, sendo considerado um crime contra a humanidade.

De acordo com o ordenamento jurídico pátrio, tem-se o art. $5^{\circ}$, incisos III da Constituição Federal aduz que "III - ninguém será submetido a tortura nem a tratamento desumano ou degradante". O inciso XLVII afirma a proibição de penas de trabalhos forçados.

Com o intuito de descontruir a imagem das vítimas escravizadas no período colonial, conforme o já discorrido anteriormente, houve a reformulação do art. 149 do Código Penal, pela Lei 10.803/2003, o qual tipifica o crime de redução da pessoa à condição análoga à de escravo, para trazer em seu bojo as formas análogas de trabalho 
comparada à escravidão. Assim, esse dispositivo criminaliza as práticas de trabalhos forçados, cerceamento da liberdade por isolamento geográfico ou dívida, jornadas exaustivas de trabalho, condições degradantes de trabalho e cerceamento de liberdade, por considera-las maneiras de reduzir o indivíduo a condição análoga à de escravo ${ }^{5}$.

Estudos da Organização Internacional do trabalho, através do seu escritório sediado no Brasil, posiciona-se em relação à alteração do art. 149 do Código Penal ao afirmar:

Com uma definição mais clara de "trabalho escravo", as leis nacionais relativas à exploração do trabalho puderam atender às características específicas do trabalho forçado no Brasil, ao mesmo tempo em que contemplaram as disposições das convenções da OIT que visam abolir a prática de trabalho forçado no mundo. Desse modo, é o artigo 149 do Código Penal Brasileiro (CPB) e a convenção da OIT $n^{\circ} 29$ que fornecem um amparo legal necessário às ações de combate ao trabalho escravo no Brasil. (OIT/ILO, 2010, p. 35) .

Destaque-se que antes da alteração, o Código Penal apenas previa tal proibição de forma genérica: “Art. 149. Reduzir alguém à condição análoga a de escravo: Pena reclusão, de 2 (dois) a 8 (oito) anos ${ }^{7}$."

Nota-se a ampliação do bem jurídico protegido, uma vez que além do cerceamento da liberdade do trabalhador, há também a proteção da sua dignidade, ao serem incluídas as condições degradantes de trabalho e as jornadas exaustivas de trabalho como modalidade de configuração do delito em análise.

\footnotetext{
${ }^{5}$ Art. 149. Reduzir alguém a condição análoga à de escravo, quer submetendo-o a trabalhos forçados ou a jornada exaustiva, quer sujeitando-o a condições degradantes de trabalho, quer restringindo, por qualquer meio, sua locomoção em razão de dívida contraída com o empregador ou preposto: Pena - reclusão, de dois a oito anos, e multa, além da pena correspondente à violência. § $1^{\circ}$ Nas mesmas penas incorre quem: I - cerceia o uso de qualquer meio de transporte por parte do trabalhador, com o fim de retê-lo no local de trabalho; II - mantém vigilância ostensiva no local de trabalho ou se apodera de documentos ou de objetos pessoais do trabalhador, com o fim de retê-lo no local do trabalho. § $2^{\circ}$ A pena é aumentada de metade, se o crime é cometido: I - contra criança e adolescente; II - por motivo de preconceito de raça, cor, etnia, religião ou origem.

${ }^{6}$ É importante mencionar que as modificações realizadas no art. 149 do CPB constitui parte da execução do acordo Solução Amistosa assinado entre o Brasil e a Comissão Pastoral da Terra, Center for Justice and International Law (Centro pela Justiça e o direito Internacional) e Human Rights Watch, momento em que o Brasil se comprometeu a envidar esforços para que o crime de redução da pessoa a condição análoga à de escravo fosse processado e julgado como crime. Em que pese as alterações terem contribuído para a punição desse crime, as penas continuaram muito baixas, não acatando a sugestão do $1^{\circ}$ Plano Nacional para a Erradicação do Trabalho Escravo, consoante Relatório CEJIL de 2007, dificultando a sua erradicação. (OIT/ILO, 2010, p. 53).

${ }^{7}$ Previsão genérica que não contribuia para a verificação das formas pelas quais se reduz uma pessoa à condição análoga à de escravo. Tal imprecisão conceitual dificultava o enfrentamento do problema da escravidão moderna objetivamente. A clareza conceitual que impera no dispositivo, ora em análise, possibilita uma melhor operacionalização da conduta contrária ao dispositivo legal.
} 
Nesse toar, Brito Filho (2016, p. 87), afirma que a apresentação analítica das formas consideradas escravocratas foi vantajosa no sentido de que houve uma ampliação das hipóteses caracterizadoras do trabalho escravo, além de ampliar o bem jurídico protegido que antes era a liberdade, para incluir a dignidade da pessoa humana. Ademais, facilitou a identificação da conduta contrária à ordem jurídica.

Em relação à competência para julgamento deste delito, o STF decidiu que apesar desse crime se encontrar inserido no Capítulo dos crimes contra a liberdade, refere-se a um crime contra a organização do trabalho de competência da justiça comum federal. A respeito desse entendimento tem-se o RE 459510/MT - Mato Grosso, cujo relator foi o Ministro Cezar Peluso, julgado em 26 de novembro de $2015 .^{8}$

Apesar do Código Penal prever de forma autoexplicativa as condutas tipificadoras do delito, apresenta duas hipóteses, jornadas excessivas e condições degradantes de trabalho, que demandam um esforço maior dos intérpretes, acarretando divergências e dificuldades para os órgãos responsáveis pelo enfrentamento do trabalho escravo. (BRITTO FILHO, 2016, p. 87).

Em relação às modalidades supramencionadas, ressalte-se que meras irregularidades trabalhistas não serão levadas em consideração para configurar a tipificação. Ademais, a ausência de uma definição penal para a jornada excessiva e condições desumanas de trabalho gera dificuldades na condenação penal.

Entrementes, em acórdão proferido Tribunal Pleno do STF, de relatoria da Min. Rosa Weber, julgado em 29 de março de 2012, decidiu-se que para a configuração do crime do at. 149 do Código Penal, não é necessário que se prove a coação física da liberdade de ir e vir ou o cerceamento da liberdade de locomoção, sendo suficiente a submissão da vítima a trabalhos forçados ou a jornada exaustiva ou a condições degradantes de trabalho. Entendeu a Corte que por ser a escravidão moderna mais sutil do que a do século XIX, a cerceamento da liberdade pode decorrer de diversos constrangimentos econômicos e não necessariamente físicos. Tratar o sujeito como coisa e não como pessoa humana pode se dar mediante a violação intensa e persistente

\footnotetext{
${ }^{8}$ Ementa: RECURSO EXTRAORDINÁRIO. CONSTITUCIONAL. PENAL. PROCESSUAL PENAL. COMPETÊNCIA. REDUÇÃO A CONDIÇÃO ANÁLOGA À DE ESCRAVO. CONDUTA TIPIFICADA NO ART. 149 DO CÓDIGO PENAL. CRIME CONTRA A ORGANIZAÇÃO DO TRABALHO. COMPETÊNCIA DA JUSTIÇA FEDERAL. ARTIGO 109, INCISO VI, DA CONSTITUIÇÃO FEDERAL. CONHECIMENTO E PROVIMENTO DO RECURSO. Disponível em: www.stf.jus.br. Acesso em 24 de setembro de 2017.
} 
de seus direitos básicos, inclusive do direito ao trabalho digno. Não é qualquer violação dos direitos trabalhistas que configura trabalho escravo. A violação aos direitos do trabalho deve ser intensa e persistente, atingir níveis gritantes e os trabalhadores serem submetidos a trabalhos forçados, jornadas exaustivas ou a condições degradantes de trabalho. Tais fatos geram o tratamento análogo ao de escravo, uma vez que os trabalhadores estão sendo privados de sua liberdade e dignidade ${ }^{9}$.

Rogério Greco posiciona-se no que concerne à jornada excessiva como sendo as horas laboradas suficientes para aniquilar completamente as forças do trabalhador, afetando sobremaneira sua saúde física e mental, o que difere da simples ausência do controle de horas. A presunção jamais poderá ser utilizada nessa análise. (GRECO, 2010).

No tocante às condições degradantes de trabalho, Britto Filho (2016) assevera que se configura com a falta de garantias mínimas de saúde, segurança e trabalho, sendo que a falta de um desses é suficiente para o reconhecimento do trabalho escravo.

Pertinente à configuração do delito, a privação da liberdade não é o fator determinante para que o crime se tipifique, sendo necessário que haja a relação de domínio entre o autor e a vítima. Outro fato importante a ser constatado é que esse domínio deve ser suficiente para anular a vontade da pessoa escravizada. (BRITTO FILHO, 2016).

Outra novidade legislativa no ordenamento jurídico pátrio foi a alteração do art. 243 da Constituição Federal pela Emenda Constitucional n ${ }^{\circ}$ 81, de 2004, passando a prever a expropriação de propriedades rurais e urbanas onde forem encontradas práticas escravocratas, assim como a apreensão de todo e qualquer bem de valor econômico encontrados nessas terras. ${ }^{1011}$ A despeito de se tratar de norma de eficácia limitada, essa

\footnotetext{
${ }^{9}$ STF. Inquérito n. 3412/AL. Rel. Min. Marco Aurélio. Relatora para acórdão Min. Rosa Weber. Julgamento: 29 de março de 2012. Órgão Julgador: Tribunal Pleno. Ementa: PENAL. REDUÇÃO À CONDIÇÃO ANÁLOGA À DE ESCRAVO. ESCRAVIDÃO MODERNA. DESNECESSIDADE DE COAÇÃO DIRETA CONTRA A LIBERDADE DE IR E VIR. DENÚNCIA RECEBIDA. Disponível em: www.stf.jus.br. Acesso em 24 de setembro de 2017.

${ }^{10}$ Art. 243. As propriedades rurais e urbanas de qualquer região do País onde forem localizadas culturas ilegais de plantas psicotrópicas ou a exploração de trabalho escravo na forma da lei serão expropriadas e destinadas à reforma agrária e a programas de habitação popular, sem qualquer indenização ao proprietário e sem prejuízo de outras sanções previstas em lei, observado, no que couber, o disposto no art. $5^{\circ}$. Parágrafo único. Todo e qualquer bem de valor econômico apreendido em decorrência do tráfico ilícito de entorpecentes e drogas afins e da exploração do trabalho escravo será confiscado e reverterá a fundo especial com destinação específica, na forma da lei.

${ }^{11}$ Trata-se de dispositivo de eficácia limitada devendo ser regulamentado por lei. A demora para a devida regulamentação gira em torno das divergências pertinentes ao conceito de trabalho escravo, como
} 
disposição constitucional adveio com o objetivo de ser mais um mecanismo para ensejar a erradicação do trabalho em condição de escravidão contemporânea.

\section{UMA TEORIA DA JUSTIÇA PARA A FUNDAMENTAÇÃO DO TRABALHO DECENTE E CONSEQUENTE ERRADICAÇÃO DO TRABALHO ESCRAVO}

A busca pela fundamentação teórica para a aplicação da justiça à realização do trabalho humano, na maioria das vezes, perpassa pela concepção marxista, muitas vezes oriundas das mudanças socioeconômicas ocorridas no fim do século XIX e início do século XX com a ascensão do Estado social, o qual teve, dentre outros fatores propulsores, os movimentos sociais voltados à proteção do indivíduo trabalhador, através do respeito aos seus direitos e garantias fundamentais de cidadão, por força da ordem econômica liberal então vigente.

Tal período teve como marco legal fundamental as Constituições do México de 1917 e de Weimar de 1919, introduzindo o poder interventor do Estado na ordem econômica como garantidor de direitos individuais e sociais. Uma das funções desse Estado interventor era garantir os direitos fundamentais do cidadão aliado aos direitos sociais, os quais passaram a limitar as liberdades econômicas. ${ }^{12}$

Em que pese a ideia de concepção de justiça fundada nos direitos sociais e coletivos, a Constituição Federal de 1988, traz, em seu art. $1^{\text {o }}$, incisos III e IV, como fundamento da República do Brasil, a dignidade da pessoa humana e os valores sociais do trabalho e da livre iniciativa. Da mesma forma, preceitua o art. $3^{\circ}$ do mesmo Texto Constitucional que são objetivos fundamentais da República Federativa do Brasil, em seu inciso I, construir uma sociedade livre, justa e solidária.

\footnotetext{
também dos termos diferentes utilizados no $\mathrm{CP}$ e na CF. Em razão dessa divergência, existem duas propostas em trâmite no Senado e na Câmara, que defendem que a existência do trabalho escravo deve ficar restrita à situação em que haja o cerceamento da liberdade. Por conta disso, esses projetos em trâmites nos órgãos referenciados objetivam retirar as duas últimas modalidades tipificadas do art. 149 do Código Penal. Segundo Britto Filho (2016, p. 92), esse delito ocorre com a subjugação do indivíduo a uma relação de domínio extremo que transmuta a sua condição de pessoa. Assim, verifica-se a violação da dignidade humana tanto na restrição da liberdade do trabalhador, quanto na imposição de jornadas extenuantes e condições degradantes de trabalho, razão pela qual entende que o termo trabalho escravo e condição análoga à de escravo são sinônimas.

${ }^{12}$ Portanto, é uma fase que marca o direito do trabalhador muitas vezes subjugados nas fábricas, sem qualquer garantia contra o trabalho insalubre, sem jornada de trabalho regulamentada e outras garantias mínimas à proteção do trabalho digno e saudável.
} 
Nesse sentido, percebe-se que o Estado Democrático de Direito traz como um dos valores fundamentais a ser alcançado e protegido pela ordem econômica constitucional, a liberdade econômica sob os aspectos da livre iniciativa, ao tempo em que garante por outros valores expressos em seu texto o alcance da justiça e da solidariedade. Tais objetivos devem gerar, dentre outros direitos e garantias, o respeito à dignidade da pessoa humana, incluindo-se nele, a valorização do trabalho.

Depreende-se dos fundamentos e objetivos constitucionais da República Federativa do Brasil que valores expressos de ordem liberal compõem o ideal de justiça social, de solidariedade e alcance à dignidade da pessoa humana. Nesse sentido, a busca pelas garantias mínimas à proteção do trabalho humano, conhecido como trabalho decente $^{13}$, pode ser analisada e dialogada com a concepção do liberalismo de princípios a partir dos ensinamentos de John Rawls. (BRITO FILHO, 2016).

Para o alcance desse fundamento, deve-se compreender o trabalho decente como o mínimo de garantias e direitos dos trabalhadores. ${ }^{14}$ Ao se garantir este mínimo existencial, aproxima-se da teoria da justiça capaz de justificar a almejada proteção ao trabalhador, o que resvalará com a erradicação do trabalho escravo contemporâneo.

Segundo John Rawls, uma sociedade democrática moderna se caracteriza por uma pluralidade de doutrinas abrangentes, religiosas, filosóficas e morais, das quais nenhum cidadão adota em seu conjunto. Segundo o autor,

O liberalismo político pressupõe que, por razões políticas, uma pluralidade de doutrinas abrangentes incompatíveis entre si é o resultado normal do exercício pelos cidadãos de sua razão no seio das instituições livres de um regime democrático constitucional. Ele pressupõe igualmente que existe pelo menos

\footnotetext{
13 Para Brito Filho (2016, p. 43), trabalho decente "é o conjunto mínimo de direitos do trabalhador, necessários à preservação de sua dignidade, e que corresponde: à existência de trabalho; à liberdade de trabalho; à igualdade no trabalho; ao trabalho com condições justas, incluindo remuneração, e que preservem sua saúde e segurança; à proibição do trabalho da criança e a restrições ao trabalho do adolescente; à liberdade sindical; e à proteção contra riscos sociais."

14 Esses direitos são considerados direitos humanos de segunda geração, constituindo os direitos econômicos, sociais e culturais. A Declaração Universal dos Direitos Humanos traz a composição dos direitos mínimos do homem trabalhador nos arts. XXIII e XXIV. Tal composição diz respeito à liberdade de escolha do trabalho, ao direito de nele encontrar condições justas de remuneração, ao respeito às horas trabalhadas e ao período de repouso. Também encontra-se, na Organização Internacional do Trabalho (OIT), os artigos que tratam da liberdade sindical, da proibição do trabalho forçado, proibição do trabalho abaixo de uma idade mínima e da proibição de discriminação. Esse conjunto mínimo de proteção ao direito do trabalhador também está previsto no Pacto Internacional dos Direitos Econômicos, Sociais e Culturais, aprovado na XXI Sessão da Assembleia Geral das Nações Unidas, em 19 de dezembro de 1966, sendo ratificado pelo Brasil em 1992. (BRITO FILHO, 2016).
} 
uma doutrina abrangente razoável que não rejeita os elementos essenciais de um regime democrático. (RAWLS, 2000, p. X-XI).

$\mathrm{O}$ autor parte do questionamento de como formar uma teoria da justiça por justaposição em uma sociedade democrática formada por diversos valores que se contrapõem, galgados por cidadãos livres e com senso de justiça. A partir de então, busca no liberalismo político uma maneira de fornecer uma concepção política de justiça independente, e que a partir de ideias políticas fundamentais, formule os valores políticos essenciais de um regime constitucional. A partir dessa construção, é possível conceber os valores do regime democrático, definindo os valores e limites que uma Constituição deve alcançar.

Para Rawls, um dos elementos que definem uma concepção política de justiça são as instituições políticas, sociais e econômicas, posto que mesmo que a concepção de justiça seja moral, é concebida em torno de um certo objeto. Essa construção se aplica à estrutura básica da sociedade, portanto, de uma estrutura constitucional moderna. Um segundo elemento refere-se à não compreensão de uma concepção política como uma concepção moral geral e abrangente, não estando comprometida com nenhuma doutrina mais ampla, devendo considerar a estrutura básica e desenvolver uma concepção razoável para a mesma. (RAWLS, 2000, p. 250-251).

Um terceiro elemento se dá pela ordenação, em função de um princípio, dos valores políticos fundamentais de uma sociedade. Rawls parte da ideia de que existe uma ideia de tradição de pensamento democrático cujo conteúdo é familiar, pelo menos intuitivamente, para todos os cidadãos. As principais instituições da sociedade podem ser consideradas um fundo de ideias e de princípios fundamentais implicitamente compartilhados, podendo ser desenvolvidos numa concepção política de justiça através do apoio de um consenso por justaposição. (RAWLS, 2010, p. 256).

Nesse sentido, ressalte-se que quando se assinala que os cidadãos são livres e iguais, significa que deve ser analisada essa concepção sob a ótica política, onde o conteúdo é observado com base nas liberdades e direitos fundamentais dos cidadãos de uma democracia, e não nos direitos filosóficos ou religiosos. Tal concepção deve ser aceita por um leque amplo de doutrinas gerais e abrangentes, portanto, por um consenso de justaposição. O objeto da justiça é a estrutura básica da sociedade, a maneira pela qual as instituições sociais mais importantes distribuem direitos e deveres fundamentais. 
Dessa forma, os princípios da justiça seriam acordados em uma situação inicial de igualdade, aceitos por pessoas livres e racionais com o fim de defender seus interesses, indicando quais seriam os princípios adequados para reger as principais instituições sociais e que revelam a escolha de dois grandes ideais políticos: a liberdade e a igualdade.

Nesse aspecto, não se admite a desigualdade que venha a gerar prejuízo a determinado indivíduo, aos menos favorecidos, posto que não há como se conceber uma concepção de justiça sem considerar cada um dos indivíduos em seus direitos mínimos como pessoa.

Assim, dentre os princípios determinados por Rawls, tem-se o de que cada pessoa deve ter um direito igual ao mais abrangente sistema total de liberdades básicas iguais que seja compatível com um sistema semelhante de liberdades para todos. Logo, as desigualdades sociais devem ser ordenadas de forma que tragam o maior benefício possível para os menos favorecidos. A teoria de Rawls introduz a igualdade como ideal político, rompendo com a visão liberal clássica, concentrada no binômio liberdadepropriedade privada. (BRITO FILHO, 2016, p. 75).

Nessa perspectiva, respeitar direitos e garantias de cada pessoa é mais do que resguardar a liberdade e a igualdade, mas respeitar uma concepção de direitos humanos como concepção de justiça, realizando-a sob as particularidades de cada pessoa dentro das liberdades políticas, de forma que a aplicação da sua teoria de justiça alcança os direitos humanos de segunda geração também. Portanto, suas ideias estão adequadas à proteção do trabalho decente e sua realização, posto que, embora sendo um direito social, também é um direito individual em sua fruição, devendo o Estado proporcionar a cada indivíduo o indispensável para que esse direito seja satisfeito.

E falar em trabalho escravo contemporâneo é justamente ir de encontro a esses direitos básicos, promovendo a sua negação. Os trabalhadores quando submetidos a condições análogas à de escravo, não usufrui os direitos referentes à consecução do trabalho decente, afetando o alcance da liberdade e da dignidade humana.

\section{CAMINHOS PARA O COMBATE DO TRABALHO ESCRAVO EM CONDIÇÃO ANÁLOGA A DE ESCRAVO}

A reformulação do art. 149 do $\mathrm{CP}$ resultou na possibilidade de criminalizar a 
conduta dos praticantes do trabalho escravo moderno. Uma outra opção para a responsabilização efetiva dessa questão é a realização do enquadramento da conduta em outros delitos conexos. ${ }^{15}$

A efetivação do enquadramento da conduta escravocrata com outros delitos conexos possibilitou uma decisão inédita da justiça Federal do Estado do Pará, com o oferecimento da denúncia pelo Ministério Público do Trabalho em 2003 e a devida condenação, em 2006, de um fazendeiro, cuja sanção resultou na aplicação de uma pena de nove anos, dos quais cinco anos seriam cumpridos em regime de detenção, pelos crimes de perigo à vida ou saúde de outrem, redução à condição análoga à de escravo, falsificação de documento público, frustação de direitos assegurado por lei trabalhista. (OIT/ILO, 2010, p. 52).

A compreensão das características e particularidades nacionais torna-se, também, imprescindível para o estabelecimento de políticas públicas aptas a combater o fenômeno da escravidão moderna. Isso porque possibilita a compreensão das razões pelas quais os trabalhadores saem da sua localidade em busca de oportunidades em outros lugares. ${ }^{16}$

Logo, torna-se evidente que a pobreza constitui um dos principais problemas socioeconômicos que corrobora para que as vítimas se submetam a essa realidade e não consigam se enxergar como vítimas desse contexto. Conclui-se, por conseguinte, que quanto menores forem o poder econômico dessas pessoas, mais estarão dispostas a se submeterem a situações desumanas nas suas relações de trabalho. Nota-se, dessa forma, que a pobreza é o fator principal pelo aumento significativo da vulnerabilidade dessas pessoas, o que favorece ao aliciamento para esse tipo de trabalho. (OIT/ILO, 2010, p. $57)$.

O conhecimento das causas estruturais da escravidão favorece para avaliar,

\footnotetext{
${ }^{15}$ Tratam-se de práticas que se relacionam ao trabalho escravo e que podem ser tipificadas como crime. São exemplos dessas figuras típicas a tortura e as lesões corporais, os danos ambientais, a violação à legislação trabalhista, o cárcere privado, o tráfico de pessoas e assassinatos. Essas conexões aumentam as possibilidades da punição dos responsáveis pela prática escravocrata, sendo que as penas referentes a cada delito são somadas. Tal combinação dos dispositivos legais representa uma medida de combate ao trabalho escravo contemporâneo. (OIT/ILO, 2010. P. 46-52).

${ }^{16}$ No Brasil, a maior quantidade de vítimas desse problema são trabalhadores com tons de pele mais escuro provenientes da região nordeste, dos estados menos desenvolvidos, com poucos recursos e desprovido de oportunidades e perspectivas de emprego. Segue-se com a região norte, especialmente nos estados do Acre, Amapá, Amazonas, Pará, Rondônia e Roraima por possuírem parte da floresta Amazônica em seus territórios, concentrando-se os casos do trabalho escravo no arco do desflorestamento. (OIT/ILO, 2010, p. 56-60).
} 
planejar e executar ações de enfretamento desse problema. Causas econômicas como a pobreza ${ }^{17}$ e a concentração fundiária ${ }^{18}$ contribuem para a existência e perpetuação dessa realidade. Acrescente-se, ainda, a falta de acesso à educação, o que aniquila de uma vez por todas as oportunidades de trabalho, dificultando o rompimento do ciclo da escravidão. (OIT/ILO, 2010, p. 111-112).

É importante destacar que a Organização Internacional do Trabalho (OIT) tem contribuído com as ações de combate através da coordenação de atividades desempenhadas pelo poder público juntamente com a sociedade civil, tanto em relação ao combate como na prevenção do trabalho escravo. (TREVISAN, 2015, p. 114).

Em relação às medidas de enfrentamento ao trabalho escravo pelo Estado brasileiro, tem-se, dentre outras, o Grupo Especial de Fiscalização Móvel (GEFM) responsável por realizar fiscalizações de forma reiteradas, o qual é gerido pelo Ministério Público do Trabalho e Emprego e é composto por auditores fiscais do Ministério do Trabalho, Polícia Federal, Polícia Rodoviária Federal, Ministério Público do Trabalho. Essas equipes libertam os trabalhadores encontrados em situação de escravidão, assegurando-lhes indenizações a que fazem jus, como também outras providências que entendam necessárias para o reestabelecimento dos diretos e dignidade desses trabalhadores. (TREVISAN, 2015, p. 115).

É importante mencionar, também, a Comissão Nacional para a Erradicação do Trabalho Escravo (CONATRAE), vinculada à Comissão Nacional de Direitos Humanos, criado em 2003, sendo responsável pela política nacional de combate ao trabalho escravo, como também pela fiscalização e implementação das ações prevista no Plano Nacional para a Erradicação do Trabalho Escravo. Importante mencionar, também, a criação do Grupo Interministerial para Erradicação do Trabalho Forçado - GERTRAF e do já mencionado Grupo Especial de Fiscalização Móvel. (NOGUEIRA, ... et al, 2015. p. 222).

Outra ação de combate importante é o cadastro de empregadores infratores,

\footnotetext{
${ }^{17}$ A pobreza interfere na realização das necessidades vitais dessa parcela da população. São trabalhadores que convivem com a ausência de renda e falta de acesso aos serviços públicos, que no último caso representa obrigações que deveriam ser garantidas pelo Estado.

${ }^{18}$ A concentração fundiária afeta, principalmente, os estados de origem das vítimas escravizadas no meio rural, por exacerbar a pobreza, uma vez que propicia a privação do único recurso disponível para a sua manutenção e da sua família nesse ambiente rural. Tal realidade corrobora com a efetivação da exploração e com a conformação dessas pessoas a condições de vida e trabalho desumanas. (OIT/ILO, 2010, p. 113).
} 
denominado também de "lista suja", criada através da portaria 540, de 15 de outubro de 2004, expedida pelo Ministério Público do Trabalho e Emprego. Essa lista relaciona os nomes dos empregadores, tanto de pessoas físicas e como de jurídicas autuadas pela prática do trabalho escravo. ${ }^{19}$

A disponibilização dessa lista ocorre através do site do Ministério do Trabalho, inclusive em páginas de internet de diversas organizações não governamentais, a exemplo da ONG Repórter Brasil. Esse cadastramento da pessoa infratora implica restrições financeiras, pois fornece informações a entidades envolvidas na eliminação do trabalho escravo. Esse cadastro serve como base de informação na avaliação de financiamentos ou empréstimos para as empresas e entre as entidades estão o Banco do Brasil, o Banco da Amazônia, o Banco do Nordeste e o Banco do Desenvolvimento Social. Frise-se, também, que as empresas signatárias do Pacto Nacional de Erradicação do Trabalho Escravo comprometem-se a não realizar transações econômicas com pessoa física ou jurídica que figuram na referida lista. (OIT/ILO, 2010, p. 146-149).

Em decisão liminar proferida em sede de Ação Direta de Inconstitucionalidade promovida pela Associação Brasileira de Incorporadoras Imobiliárias (ABRAINC), o então Ministro Presidente do STF Ricardo Lewandowiski, destacou que os gestores públicos devem observar os preceitos constitucionais. Assim, explicou que muito embora se mostre louvável a intenção de criar o cadastro de empregadores, verificou a inexistência de lei formal que respaldasse a edição da portaria interministerial $\mathrm{n}$. 02/2011, assinada pelo Ministério do Trabalho e a secretaria Especial de Direitos Humanos, a qual revogou a portaria 540/2004, trazendo regras novas para a inclusão de empregadores na lista suja. Com isso, verificou-se que a decisão liminar citada suspendeu os efeitos da Portaria interministerial n. 02/2011 e, consequentemente, a portaria $540 / 2004^{2021}$.

\footnotetext{
${ }^{19}$ A portaria n. 540/2004 do Ministério Público do Trabalho e Emprego constitui um ato infralegal de caráter administrativo que tem como função regulamentar os procedimentos de fiscalização e apuração do correto cumprimento da legislação trabalhista. Importante mencionar que a inclusão dos empregadores infratores ocorrerá após decisão administrativa final referente ao auto de infração lavrado através de fiscalização com a identificação da ocorrência da prática escravocrata. Tal lista deverá ser atualizada semestralmente e encaminhada para os seguintes órgãos: Ministério do Meio Ambiente, Ministério do Desenvolvimento Agrário, Ministério da Integração Nacional, Ministério da Fazenda, Ministério Público do Trabalho, Ministério Público Federal, Secretaria Especial de Direitos Humanos e Banco Central. O infrator será monitorado por um período de dois anos, sendo que não havendo a reincidência e após o pagamento de todas as multas e débitos trabalhistas, ocorrerá a sua exclusão da referida lista.

${ }^{20}$ Ementa: AÇÃO DIRETA DE INCONSTITUCIONALIDADE. PORTARIA INTERMINISTERIAL N. 02/2011. CADASTRO DE EMPREGADORES QUE TENHAM SUBMETIDO TRABALHADORES A CONDIÇÕES ANÁLOGAS A DE ESCRAVO. ATO NORMATIVO REVOGADO. PERDA SUPERVENIENTE DE OBJETO. AÇÃO DIRETA DE INSCONSTITUCIONALIDADE JULGADA PREJUDICADA. Disponível em: www.stf.jus.br. Acesso em 24 de setembro de 2017.

${ }^{21}$ A portaria interministerial $\mathrm{n}$. 02/2011 foi posteriormente revogada pela portaria interministerial $\mathrm{n}$. 02/2015, motivo pelo qual foi julgado prejudicado o mérito da ADI n. 5209/DF. Essa portaria foi
} 
O fundamento utilizado pelo autor da Ação Direta de Inconstitucionalidade n. 5209/DF foi que a citada portaria interministerial n. 02/2011 viola os artigos 87,II e 186, III e IV da Constituição Federal, usurpando a competência do Poder Legislativo, criando nova competência para os auditores fiscais do trabalho.

A portaria interministerial n. 04/2016 não vinha sendo cumprida por estar sendo revisada por grupo de trabalho instituído no âmbito do Órgão Ministerial, tendo em vista que foram constatadas falhas e imperfeições no documento. Nesse sentido, segundo a União Federal, a divulgação da lista seria temerária, uma vez que seria impossível averiguar a extensão dos efeitos negativos e contundentes que recairiam sobre os envolvidos após a divulgação dos dados. ${ }^{22}$

Em face da não aplicação da portaria interministerial n. 04/2016, o Ministério Público do Trabalho uma Ação Civil Pública n. ACP-1704-55.2016.5.10.0011, da lavra do subprocurador-geral do trabalho Manoel Jorge e Silva Neto, distribuída na $11^{\mathrm{a}}$ Vara do Trabalho do Distrito Federal, obtendo decisão liminar para determinar à União Federal que divulgasse o cadastro dos empregadores infratores. Contra a concessão da liminar, a União moveu pedido de suspensão de segurança em caráter liminar junto ao presidente do TST para suspender os efeitos da decisão proferida pelo juiz da $10^{\mathrm{a}}$ Vara do Trabalho do Distrito Federal. Esse pedido da União foi acolhido pelo Presidente do TST, Min. Ives Gandra Martins Filho adiando a divulgação da chamada lista suja. Contra esta decisão foi impetrado Mandado de Segurança pelo Ministério Público do Trabalho para cassar a decisão proferida pela presidência do $\mathrm{TST}^{23}$.

Nesse sentido, vale destacar o pedido do Ministério Público do Trabalho, através do subprocurador-geral do trabalho Manoel Jorge e Silva Neto, para a publicação da lista suja, reforça que esse Cadastro de Empregadores envolvidos com práticas em condições análogas à de escravo é medida eficiente no "combate à escravidão contemporânea, que se alicerça na superexploração gananciosa da mão de obra humana e no aviltamento de direitos trabalhistas mínimos". ${ }^{24}$

Finalmente, é importante salientar que a OIT assevera que os juízes têm o dever de decidir os casos referentes à exploração laboral em condições análogas à de escravo, mesmo encontrando dificuldades na interpretação dos novos dispositivos legais, podendo-se afirmar que a decisões dos magistrados, nas diversas esferas do

posteriormente também revogada pela portaria interministerial n. 04/2016, a qual reproduziu o núcleo essencial da portaria n. 02/2015, acrescendo a possibilidade de celebração de termo de ajuste de conduta ou acordo judicial para a reparação do dano causado pelo administrado, alvo da fiscalização.

${ }^{22}$ Vide inteiro teor da ADI 5209/DF de relatoria da MIN. Carmen Lúcia. Disponível em: www.stf.jus.br

${ }^{23}$ Vide inteiro teor do Mandado de Segurança n. ${ }^{\circ}$ TST-MS-3351-63.2017.5.00.0000. Disponível em: http://cdn01.justificando.cartacapital.com.br/wp-content/uploads/2017/03/16143900/41157_2017_14895 28800000.pdf

${ }^{24} \mathrm{O}$ subprocurador-geral do trabalho aduziu, em seu pedido, que a portaria interministerial n. 04/2016 tem por finalidade dar transparência aos atos administrativos resultantes de ações fiscais que flagraram a exploração do trabalho a condições análogas a de escravo, e que o retardo quanto a publicação enseja dano irreparável a sociedade como um todo. 
poder judiciário, têm favorecido bastante para a erradicação desse problema. (TREVISAN, 2015, p. 129).

Desta forma, percebe-se que o Brasil tem empreendido esforços no combate a este mal, principalmente no que diz respeito à fiscalização de propriedades, com a devida punição administrativa e econômica dos empregadores que forem encontrados desenvolvendo a prática da escravidão.

Papel também relevante é o desenvolvido pela Corte Interamericana de Direitos Humanos, instituição judicial autônoma da Organização dos Estados Americanos (OEA) que tem como função precípua analisar, instruir e julgar situações que envolvam a violação dos direitos humanos e fundamentais. Esta Corte, recentemente, responsabilizou internacionalmente o Estado brasileiro - caso trabalhadores da fazenda Brasil Verde- por não prevenir a prática de trabalho escravo moderno e de tráfico de pessoas. ${ }^{25}$

\section{CONCLUSÃO}

O trabalho escravo contemporâneo é constatado, ainda, nos tempos hodiernos, ensejando a inefetividade de direitos humanos dos trabalhadores consagrados na Constituição Federal, na Consolidação das Leis do Trabalho e em diversos dispositivos internacionais ratificados pelo Brasil.

As relações humanas estão cada vez mais fragilizadas, contribuindo sobremaneira para o desgaste progressivo das relações de trabalho. Vislumbra-se que a escravidão se estabelece, não mais predominantemente no âmbito rural, também na seara urbana, com a intensificação das migrações e de trabalhadores indocumentados. Existe um conjunto de fatores sociais cuja marca central é a pobreza, que é responsável pela submissão desses trabalhadores aos detentores do poder econômico, o que faz com que as vítimas escravizadas não se reconheçam como tal.

A utilização do trabalho escravo é uma realidade na sociedade, embora não seja tão visível. Fruto de uma desigualdade socioeconômica expressiva em nosso país,

\footnotetext{
${ }^{25}$ A decisão determinou aos cofres públicos o pagamento de 5 milhões de dólares às 128 vítimas resgatadas durante fiscalizações do Ministério Público do Trabalho nos anos de 1997 a 2000. Segundo a Corte, o Poder Judiciário é cúmplice da discriminação desses trabalhadores escravizados. Assim como, determinou as reaberturas das investigações sobre as violações cometidas contra esses trabalhadores, abrindo precedentes para a reabertura de casos já arquivados. Revista Consultor Jurídico de 17/12/2016. Disponível em: www.conjur.com.br. Acesso em: 24 de setembro de 2017.
} 
nota-se situações de miséria, resvalando questões sociais que representam a situação de vulnerabilidade das vítimas por se encontrarem fragilizadas devido à sua condição social, o que corrobora para o fato de se tornar alvo fácil para os autores deste tipo de delito.

Diante dessa situação, as vítimas escravizadas entram na engrenagem desse sistema apenas com o objetivo de sobrevivência, acreditando ser a única oportunidade que possui. Na realidade, são impelidas a se submeterem a condições desumanas, colocando sua vida em risco, quando são reduzidas à condição análoga a de escravo.

Nesse contexto, é de fundamental importância empreender um olhar para as vítimas escravizadas no sentido de reconhecê-las como sujeito de direitos.

Ressalte-se que esse problema deverá ser enfrentado não apenas com a penalização do empregador, porque não resolve de imediato a vulnerabilidade da vítima escravizada, mas deve ser enfrentado sob o viés da promoção da qualificação e da informação necessárias às vítimas que se encontram nesta situação. O fato de não possuírem conhecimento é condicionante para a submissão à condição laborativa em análise.

É imprescindível o enfrentamento da vulnerabilidade das vítimas das práticas escravocratas porque estão inseridas num processo cultural oriundo do processo socioeconômico, não se reconhecendo como escravos, posto que vivenciam a falta de oportunidades concretas, responsáveis pelo tolhimento da capacidade de reescrever suas histórias da forma que almejam.

O estabelecimento de políticas públicas concretas com a disponibilização de cursos alfabetizantes e profissionalizantes, para que essas vítimas consigam se libertar do ciclo vicioso da escravidão moderna, o que só será viável com a conscientização social para a existência da escravidão e com a eliminação da situação de vulnerabilidade dessas pessoas.

Por conseguinte, evidencia-se a necessidade de trazer esse tema para discussão acadêmica, no sentido de que sejam debatidos caminhos para erradicação da prática de trabalho em condições análogas a de escravo, aprimorando os planos de ações para a concretização de políticas públicas efetivas para a prevenção e combate deste fenômeno econômico-social tão desumano.

\section{REFERÊNCIAS}


ANDRADE, Shirley Silveira. Trabalho escravo contemporâneo: a divergência conceitual entre a liberdade de ir e vir e a dignidade de viver. Revista Superior da Magistratura Tocantinense (ESMAT). Palmas, n. 9, p. 193-223, jan/jun. 2015.

ARENDT, Hannah. Origem do Totalitarismo. Tradução Roberto Raposo. São Paulo: Companhia das Letras, 2012.

BRITO FILHO, José Cláudio Monteiro de. Teorias da justiça e trabalho decente. In: Direitos Humanos dos Trabalhadores. Rúbia Zanotelli de Alvarenga (org). São Paulo: LTr Editora, 2016.

. Trabalho com redução do homem a condição análoga à de escravo e a dignidade da pessoa humana. Disponível em: http://www.pgt.mpt.gov.br/publicações. Acesso em 08/05/2017.

Trabalho decente: análise jurídica da exploração do trabalho - trabalho escravo e outras formas de trabalho indigno. 4.ed. São Paulo: LTR, 2016.

2 ed. São Paulo: LTr Editora, 2017.

Trabalho escravo: caracterização jurídica.

GÓMEZ, Rina Cáceres. El trabajo esclavo em Costa Rica. Revista de História, [S.I.], n. 39, july 2001. ISSN 2215-4744. Disponível em: $<$ http://www.revistas.una.ac.cr/index.php/historia/article/view/2023> . Acesso em: 28 de julho de 2017.

GRECO, Rogério. Curso de Direito Penal: parte especial, vol. II: introdução à teoria geral da parte especial: crimes contra a pessoa. $7^{\mathrm{a}}$ ed. Niterói: Ímpetos, 2010.

NOGUEIRA, Christiane; NOVAES, Marina; BIGNAMI, Renato, et al. Tráfico de pessoas e trabalho escravo: além da interposição de conceitos. In: Revista do Ministério Público do Trabalho/ Procuradoria Geral do Trabalho. Brasília, Ano XXIII. N. 46. Setembro de 2015, p. 217-243.

ORGANIZAÇÃO DAS NAÇÕES UNIDAS. ONU. Declaração Universal dos Direitos Humanos. Resolução n 217 A (III) da Assembleia Geral das Nações Unidas. Dez. 1948. Disponível em: <http://www.direitoshumanos.usp.br/index.php/DeclaraçãoUniversal-dos-Direitos-Humanos/declaracao-universal-dos-direitos-humanos.html>.

Acesso em, 30 de maio de 2016.

ORGANIZAÇÃO INTERNACIONAL DO TRABALHO. OIT. Combatendo o trabalho escravo contemporâneo: o exemplo do Brasil. International Labour Office/ILO Office in Brasil. Brasília: ILO, 2010. (Livro digital).

ORGANIZAÇÃO INTERNACIONAL DO TRABALHO. OIT. Convenção 29 Convenção concernente à trabalho forçado ou obrigatório, adotada pela Conferência em sua Décima Quarta Sessão - Genebra, 28 de junho de 1930 (com as modificações da Convenção de Revisão dos artigos finais, de 1946). Disponível em: <http:// http://www.planalto.gov.br/ccivil_03/decreto/antigos/d41721.htm>. Acesso em $20 \mathrm{de}$ abril de 2017.

ORGANIZAÇÃO INTERNACIONAL DO TRABALHO. OIT. Convenção 105 Convenção concernente à abolição do trabalho forçado, promulgado pelo Decreto $\mathrm{n}^{\mathrm{o}}$ 
58.822, de 14 de julho de 1966. Disponível em: $<$ http://www.planalto.gov.br/ccivil_03/decreto/1950-1969/D58822.htm>. Acesso em 20 de abril de 2017.

PIOVESAN, Flávia. Direitos Humanos e Justiça Internacional. $6^{\text {a }}$ edição. São Paulo: Saraiva, 2015a.

PIOVESAN, Flávia. Temas de Direitos Humanos. $8^{\text {a }}$ ed. São Paulo: Saraiva, 2015b.

RAWLS, John. Justiça e democracia. Irene A. Paternot. São Paulo: Martins Fontes, 2000.

REVISTA CONSULTOR JURÍDICO. Em decisão inédita, Corte Interamericana condena Brasil por trabalho escravo. 17 de dezembro de 2016. Disponível em: www.conjur.com.br. Acesso em: 24 de setembro de 2017.

ROGRÍGUEZ, Vanesa. Prohibición de esclavitud y servidumbre. In: Convención Americana de Derechos Humanos y su proyeción en el Derecho Argentino. 1 ed. Buenos Aires: La Ley/Departamento de Publicaciones de la Facultad de Derecho, 2013.

SARLET, Ingo Wolfgang. A eficácia dos direitos fundamentais: uma teoria geral dos direitos fundamentais na perspectiva constitucional. 12 edição. Porto Alegre: Livraria do Advogado Editora, 2015.

TREVISAN, Elisaide. Trabalho Escravo no Brasil Contemporâneo: entre as presas da clandestinidade e as garras da exclusão. Curitiba: Juruá, 2015. 